\title{
STRUKTUR KOMUNITAS PADANG LAMUN DI PERAIRAN PANTAI PANDAWA, BALI
}

\section{COMMUNITY STRUCTURE OF SEAGRASS BEDS IN PANDAWA BEACH AQUATIC, BALI}

\author{
Kadek Bayu Prabha Mahesswara ${ }^{1}$, Ni Luh Watiniasih², I Wayan Darya Kartika ${ }^{3}$ \\ 1. Program Studi Manajemen Sumberdaya Perairan, Fakultas Kelautan dan Perikanan, Universitas \\ Udayana, Bukit Jimbaran, Kabupaten Badung, Bali-Indonesia. \\ 2. Fakultas Matematika dan Ilmu Pengetahuan Alam, Universitas Udayana, Bukit Jimbaran, Kabupaten \\ Badung, Bali-Indonesia. \\ Email: luhwatinasih@unud.ac.id
}

\begin{abstract}
ABSTRAK
Penelitian ini bertujuan untuk mengetahui jenis dan struktur komunitas lamun berdasarkan kepadatan jenis, kerapatan relatif spesies, indeks keanekaragaman, indeks keseragaman, dan indeks dominansi lamun. Penelitian ini dilakukan di sepanjang Pantai Pandawa, Desa Kutuh, Kecamatan Kuta Selatan, Kabupaten Badung, Bali dari November hingga Desember 2019. Data lamun dikumpulkan dari 3 transek garis, 3 transek kuadran dan diulang 3 kali. Data kualitas air dikumpulkan 3 kali dalam 4 minggu. Terdapat 8 jenis lamun yang teridentifikasi, yaitu: Thalassia hemprichii, Cymodocea serrulata, Halodule pinifolia, Halodule uninervis, Halophila ovalis, Halophila decipiens, Syringodium isoetifolium, dan Thalassodendron ciliatum. Kerapatan spesies tertinggi yang ditemukan di stasiun I adalah Thalassodendron ciliatum, serta kerapatan relatifnya, dan yang terendah adalah Thalassia hemprichii. Pada stasiun II dan III, kerapatan spesies tertinggi ditemukan pada jenis Cymodocea serrulata dan terendah ditemukan pada jenis Halophila ovalis. Studi ini menemukan bahwa kerapatan spesies lamun di Pantai Pandawa dikategorikan sebagai kerapatan tinggi, yang didominasi oleh Thalassodendron ciliatum di stasiun I, dan Cymodocea serrulata di stasiun II dan III. Indeks keanekaragaman jenis lamun di stasiun I dan II dikategorikan sebagai keanekaragaman spesies sedang dan keanekaragaman spesies rendah untuk stasiun III. Indeks dominasi jenis lamun di tiga stasiun dikategorikan sebagai dominan tinggi. Indeks keseragaman jenis lamun dikategorikan sebagai komunitas sedang atau tidak stabil untuk stasiun I dan II, dan kesamaan rendah untuk stasiun III.
\end{abstract}

\section{Kata kunci: struktur komunitas, lamun, Pantai Pandawa.}

\section{ABSTRACT}

This research aimed to determine the types and structure of seagrass community based on species density, species relative density, diversity index, uniformity index, and dominance index of the seagrass. This research was conducted along Pandawa Beach, Kutuh Village, South Kuta District, Badung Regency, Bali from November to December 2019. Data of seagrass were collected from 3 line transects, 3 kuadran transects from each transect, repeated 3 times. Water quality data were collected 3 times within 4 weeks. Eight species of seagrass were identified, namely: Thalassia hemprichii, Cymodocea serrulata, Halodule pinifolia, Halodule uninervis, Halophila ovalis, Halophila decipiens, Syringodium isoetifolium, and Thalassodendron ciliatum. The highest species density found at station I that was Thalassodendron ciliatum, as well as for its relative density, and the lowest was Thalassia hemprichii. At station II and III, the highest species density was found on Cymodocea serrulata and the lowest was on Halophila ovalis. The study found that the species density of seagrasses at Pandawa Beach was categorized as high density, which dominated by Thalassodendron ciliatum at station I and by Cymodocea serrulata at station II and III. Diversity index of seagrass species at station I and II was categorized as medium species diversity and low species 
diversity for the station III. Dominance index of seagrass species at the three station was categorized as high dominance. Similarity index of seagrass species was categorized as medium or unstable community for the station I and II, and low similarity for the station III.

Keywords: community structure, seagrass, Pandawa Beach

\section{PENDAHULUAN}

Lamun (seagrass) adalah tumbuhan tingkat tinggi (Anthophyta) yang hidup dan tumbuh terbenam di lingkungan laut; berpembuluh, berimpang (rhizome), berakar, dan berkembang biak secara generatif (biji) dan vegetatif. Rimpangnya merupakan batang yang beruas-ruas, tumbuh terbenam dan menjalar dalam substrat pasir, lumpur dan pecahan karang (Sjafrie et al., 2018). Ekosistem lamun memiliki peranan yang penting dalam menunjang kehidupan berbagai jenis makhluk hidup.

Fungsi dan peranan lamun bergantung pada jumlah helaian daun, panjang daun, lebar daun, serta biomassa total, sangat ditentukan kondisi setempat (Wangkanusa et al., 2017). Padang lamun memiliki peran penting sebagai sumber utama produktivitas primer atau penghasil bahan organik, juga habitat untuk berbagai biota, tempat asuhan, tempat memijah, sumber makanan bagi biota langka dan penyokong keanekaragaman jenis-jenis biota laut, serta bernilai ekonomis dari jasa ekosistem lamun (Supriyadi et al., 2018). Apabila dinilai dari fungsi padang lamun yang telah dijelaskan, keberadaan lamun harus tetap terjaga.

Lamun tumbuh padat membentuk padang, sehingga dikenal sebagai padang lamun (seagrass beds). Lamun dapat tumbuh membentuk padang lamun dengan kepadatan mencapai 4.000 tumbuhan per $\mathrm{m}^{2}$ dan mempunyai biomassa tetap sebesar $2 \mathrm{~kg} / \mathrm{m}^{2}$. Padang lamun dapat membentuk vegetasi tunggal, tersusun atas satu jenis lamun yang tumbuh membentuk padang lebat, sedangkan vegetasi campuran terdiri dari 2 - 12 jenis lamun yang tumbuh bersama-sama pada satu substrat. Spesies lamun yang biasanya tumbuh dengan vegetasi tunggal adalah Thalassia hemprichii, Enhalus acoroides, Halophila ovalis, Halodule uninervis, Cymodocea serrulata, dan Thalassodendrom ciliatum (Wagey dan Sake, 2013). Salah satu pantai di Bali yang terdapat padang lamun adalah Pantai Pandawa. Berkembangnya pantai Pandawa sebagai salah satu tujuan wisata, diperkirakan dapat berpengaruh terhadap keberadaan padang lamun di pantai Pandawa, sehingga perlu dilakukan pendataan melalui penelitian terhadap komunitas padang lamun di pantai tersebut. Perkembangan pariwisata di pantai Pandawa tidak menutup kemungkinan akan dikembangkan lagi, sehingga dapat berpengaruh terhadap luasan maupun pertumbuhan padang lamun. Oleh karen itu data yang didapat dari penelitian ini dapat menggambarkan kondisi lamun saat ini dan perubahan yang terjadi.

\section{LOKASI PENELITIAN}

Penelitian ini dilakukan pada bulan November-Desember 2019 di Perairan Pantai Pandawa, Desa Kutuh, Kecamatan Kuta Selatan, Kabupaten Badung-Bali. 


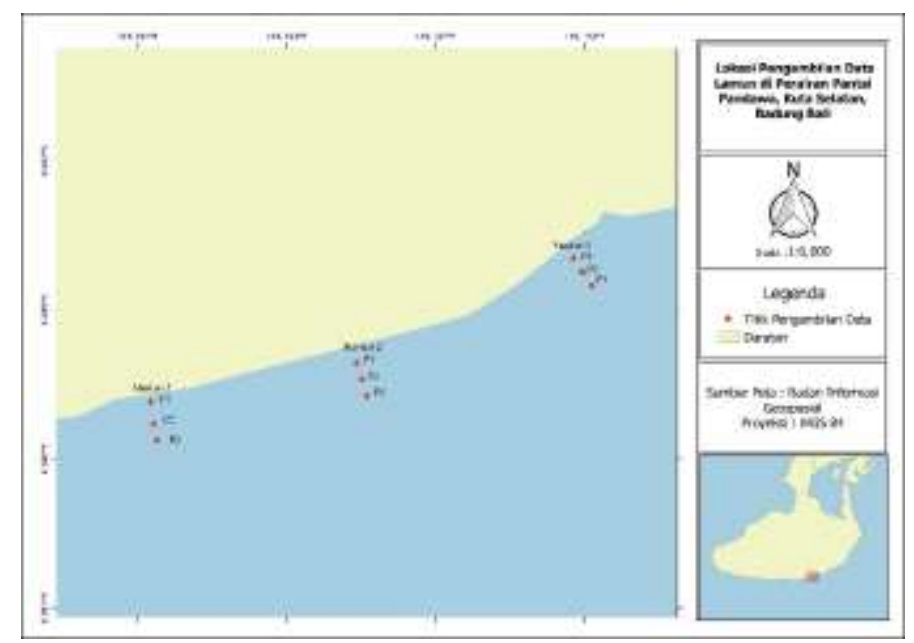

Gambar 1. Peta Lokasi Penelitian

\section{METODE}

Metode yang digunakan dalam penelitian ini yaitu metode deskriptif, dengan metode pengambilan sampel Random Sampling terhadap Ekosistem Lamun yang terdapat di Perairan Pantai Pandawa. Pengambilan data struktur komunitas lamun dilakukan dengan pengumpulan data primer terhadap kerapatan jenis dan relatif, indeks keanekaragaman, indeks keseragaman dan indeks dominansi Lamun yang terdapat di Perairan Pantai Pandawa.
Penetuan stasiun pada penelitian ini dilakukan dengan cara Purposive Sampling seperti pada Gambar 2. Penentuan stasiun berdasarkan tingkat aktivitas pariwisata yang terdapat di Pantai Pandawa. Masingmasing stasiun terdapat 3 titik tegak lurus kearah laut dengan jarak antar titik \pm 35 meter dan di setiap titik dilakukan pengulangan sebanyak 3 kali. Stasiun I dengan tingkat aktivitas pariwisata sedang, stasiun II dengan tingkat aktivitas pariwisata tinggi dan stasiun III dengan tingkat pariwisata rendah.

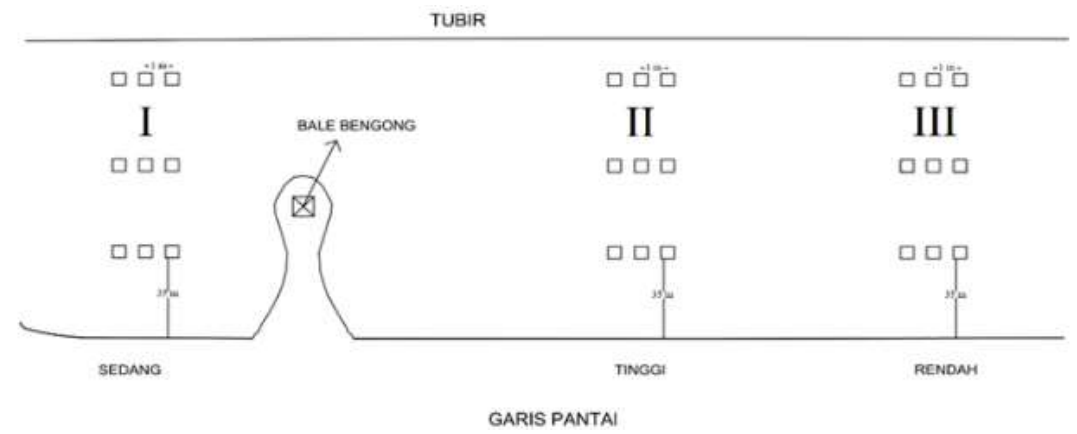

Gambar 2. Penentuan Stasiun Pengambilan Sampel

$\begin{array}{lll}\text { Identifikasi } & \text { sampel lamun } & 50 \times 50 \mathrm{~cm} \text {. Kuadrat dibagi menjadi } 15 \text { plot } \\ \text { dilakukan secara insitu. Acuan untuk } & \text { kecil dengan ukuran } 15 \times 15 \mathrm{~cm} \text { (Gambar } \\ \text { mengidentifikasi jenis lamun menggunakan } & 3 \text { ).. }\end{array}$

Buku Status Padang Lamun Indonesia (Sjafrie et al. 2018). Pengamatan Lamun dilakukan menggunakan metode kuadrat. Ukuran kuadrat yang digunakan sebesar 


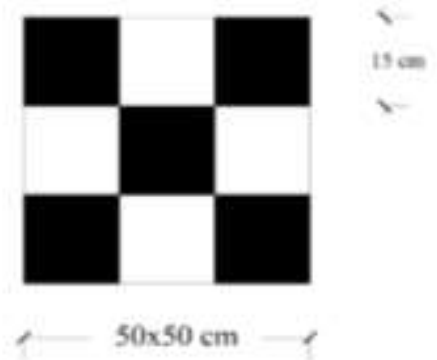

Gambar 3. Sketsa plot Pengambilan Sampel

\section{ANALISIS DATA}

1. Kerapatan Jenis dan Kerapatan Relatif

Kerapatan jenis dan kerapatan relatif dihitung mengikuti Gemilang et al. (2016):

$D i=\frac{n i}{A}$

dimana Di adalah kerapatan jenis (tegakan/m2); ni adalah jumlah total individu; dan A adalah jumlah luas area pengukuran (m2).

$R D i=\frac{D i}{\sum D} \times 100 \%$

dimana RDi adalah kerapatan relatif (\%); Di adalah kerapatan jenis (tegakan/m2); dan $\sum D$ adalah kerapatan seluruh jenis. Menurut Gosari dan Haris (2012), kriteria kerapatan relatif lamun dibagi menjadi 5 kategori, yaitu:

$$
\begin{array}{ll}
\text { RDi }>175 & \text { : Sangat rapat } \\
125-175 & : \text { Rapat } \\
75-125 & \text { : Agak rapat } \\
25-75 & \text { : Jarang } \\
\text { RDi }<25 & \text { : Sangat jarang }
\end{array}
$$

\section{Indeks Keanekaragaman}

Indeks keanekaragaman dihitung mengikuti Indeks Keanekaragaman
Shannon-Wiener (H'), mengacu pada Pratiwi dan Ernawati (2018):

$$
H^{\prime}=-\sum_{i=1}^{n} p i \ln p i
$$

$$
\text { dimana H' adalah Indeks }
$$

Keanekaragaman Shannon-Wiener; dan pi merupakan perbandingan jumlah spesies ke-i (ni) terhadap jumlah total pi. $\mathrm{pi}=$ ni $/ \mathrm{N}$. Kriteria indeks keanekaragaman dibagi menjadi 3 kategori (Insafitri, 2010), yaitu:

$$
\begin{array}{ll}
\mathrm{H}^{\prime}<1 & \begin{array}{l}
: \text { Keanekaragaman jenis } \\
\text { rendah }
\end{array} \\
1<\mathrm{H}^{\prime}<3 & \begin{array}{l}
: \text { Keanekaragaman jenis } \\
\text { sedang } \\
: \text { Keanekaragaman jenis } \\
\text { tinggi }
\end{array} \\
\mathrm{H}^{\prime}>3 &
\end{array}
$$

\section{Indeks Keseragaman}

Indeks keseragaman dihitung mengikuti Indeks Keseragaman ShannonWiener (E), mengacu pada Suherlan et al., (2016):

$$
\begin{aligned}
E= & \frac{H^{\prime}}{\mathrm{H} / \mathrm{max}} \\
& \text { dimana } \mathrm{E} \text { merupakan indeks }
\end{aligned}
$$
keseragaman Shannon-Wiener (berkisar antara $0-1) ; \quad H^{\prime}$ adalah indeks keanekaragaman Shannon-Wiener; dan H'maks adalah indeks keanekaragaman maksimal.

Dengan kriteria (Madduppa, 2016) sebagai berikut:

$0<\mathrm{E} \leq 0,5 \quad$ : Keseragaman jenis rendah $0,5<\mathrm{E} \leq 0,75$ : Keseragaman jenis sedang $0,75<\mathrm{E} \leq 1 \quad$ : Keseragaman jenis tinggi

\section{Indeks Dominansi}

Perhitungan indeks dominansi dilakukan untuk mengetahui tingkat dominansi spesies di suatu perairan. Persamaan yang digunakan untuk 
menghitung indeks dominansi menggunakan Indeks Dominansi Simpson yang mengacu pada penelitian Suherlan et al. (2016):

$$
\mathrm{C}=\sum_{i=1}^{S}(n i / N)^{2}
$$

dimana $\mathrm{C}$ adalah indeks dominansi Simpson; ni adalah jumlah individu jenis ke-i; $\mathrm{N}$ adalah jumlah total individu dari semua spesies; s adalah jumlah spesies. Kriteria indeks dominansi dibagi menjadi 3 (Madduppa, 2016), yaitu:

$0<\mathrm{C}<0,5 \quad$ : Dominansi rendah $0,5<\mathrm{C} \leq 0,75$ : Dominansi sedang $0,75<\mathrm{C} \leq 1 \quad$ : Dominansi tinggi

\section{HASIL DAN PEMBAHASAN}

\section{Parameter Fisika-Kimia Perairan}

Parameter fisika-kimia perairan yang diukur pada penelitian ini yaitu suhu, salinitas, kekeruhan, kecepatan arus, $\mathrm{pH}$ (Derajat Keasaman) dan DO (Dissolved Oxygen). Pengukuran dilakukan tiga kali selama satu bulan pada setiap stasiun. Hasil pengukuran parameter fisika-kimia perairan Pantai Pandawa dapat dilihat pada Gambar 4.

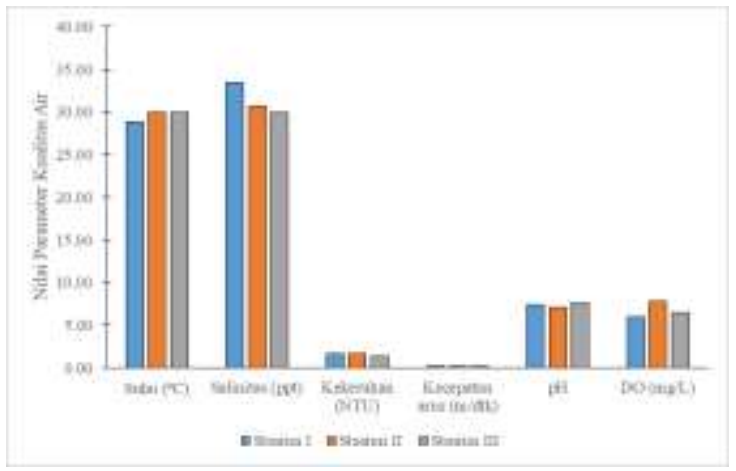

Gambar 4. Parameter Fisika-Kimia Perairan

Suhu terendah didapat pada stasiun I yaitu dengan nilai $28,83{ }^{\circ} \mathrm{C}$, sedangkan suhu pada stasiun II dan III memiliki nilai tertinggi yaitu $30{ }^{\circ} \mathrm{C}$. Kisaran tersebut masih dalam kategori baik untuk pertumbuhan lamun. Hal ini sesuai dengan pernyataan Sakaruddin (2011), yaitu lamun dapat tumbuh pada kisaran $5-35{ }^{\circ} \mathrm{C}$ dan tumbuh dengan baik pada kisaran suhu $25-$ $30{ }^{\circ} \mathrm{C}$, sedangkan pada suhu di atas $45^{\circ} \mathrm{C}$ lamun akan mengalami stres dan dapat mengalami kematian di perairan Sulawesi Utara.

Salinitas tertinggi berada pada stasiun I dengan nilai 33,5 ppt dan salinitas terendah terdapat pada stasiun III dengan nilai 30 ppt dengan nilai rata-rata salinitas yaitu 31,4 ppt. Kisaran salinitas yang dapat ditolerir tumbuhan lamun adalah 10 - 40 ppt, dengan nilai optimum untuk lamun dapat tumbuh dengan baik adalah $35 \mathrm{ppt}$ (Wirawan, 2014).

Kekeruhan pada stasiun I dan II hampir sama yaitu sebesar 1,6 dan 1,62 sedangkan nilai kekeruhan pada stasiun III yaitu 1,32 yang artinya perairan pada stasiun III lebih cerah. Berdasarkan hal tersebut, bahwa kekeruhan pada perairan Pantai Pandawa masih tergolong sesuai untuk keberlangsungan ekosistem lamun. Hal ini sesuai dengan Fahruddin et al. (2017), bahwa nilai kekeruhan yang sesuai untuk keberlangsungan ekosistem lamun yaitu <5 NTU.

Kecepatan arus di perairan Pantai Pandawa termasuk kedalam kategori arus sedang (Sari dan Usman, 2012), dengan nilai rata-rata dari ketiga stasiun adalah 0,36 m/dtk. Padang lamun di perairan Pantai Pandawa dapat berproduktivitas dengan baik (Nurzahraeni, 2014). Lebih jauh dijelaskan bahwa produktivitas padang lamun dipengaruhi keadaan kecepatan arus perairan, dengan kemampuan maksimum untuk "Standing Crop" pada kecepatan arus sekitar 0,5 m/dtk (Nurzahraeni, 2014). 
Kadar oksigen terlarut di perairan Pantai Pandawa masih dalam kisaran yang ideal untuk pertumbuhan biota laut dan ekosistem lamun dengan nilai rata-rata sebesar 6,73 mg/L. Hal tersebut sesuai dengan pernyataan Hamuna et al. (2018), bahwa kadar oksigen terlarut dalam air yang ideal untuk biota laut yaitu berkisar antara $3-7 \mathrm{mg} / \mathrm{L}$.

Kisaran $\mathrm{pH}$ untuk air laut berkisar antara 7,8-8,2, dan nilai $\mathrm{pH}$ yang optimum untuk pertumbuhan lamun berkisar antara 7,3 - 9,0 (Tahril et al., 2011). Nilai rata-rata $\mathrm{pH}$ perairan Pantai Pandawa dimana lamun tumbuh senilai 7,38, dimana menurut Tahril et al. (2011) nilai tersebut berada pada kisaran optimum untuk pertumbuhan lamun.

Kualitas air yang didapat pada penelitian ini menunjukkan bahwa perairan Pantai Pandawa masih baik untuk pertumbuhan ekosistem lamun. Hal ini didukung dengan tingginya kerapatan jenis yang ditemukan dengan substrate tempat tumbuh dan kecepatan arus yang masih mendukung kehidupan lamun di pantai Pandawa. Minerva et al. (2014) menegaskan bahwa kerapatan jenis lamun dengan kualitas air memiliki korelasi yang sangat erat.

\section{Jenis-Jenis Lamun di Perairan Pantai Pandawa}

Jenis-jenis lamun yang ditemukan di perairan Pantai Pandawa pada penelitian ini sebanyak 8 jenis di 3 stasiun yang telah ditentukan. Klasifikasi berdasarkan buku identifikasi oleh Faishol et al. (2016), dimana lamun termasuk ke dalam kelas Angiospermae dengan famili, genus dan spesies seperti pada Tabel 1 .

Tabel 1. Jenis-Jenis Lamun Yang Ditemukan

\begin{tabular}{lll}
\hline \multicolumn{1}{c}{ Famili } & \multicolumn{1}{c}{ Genus } & \multicolumn{1}{c}{ Spesies } \\
\hline Hydrocaritaceae & Thalassia & Thalassia hemprichii \\
Hydrocaritaceae & Halophila & Halophila ovalis \\
Hydrocaritaceae & Halophila & Halophila decipiens \\
Potamogetonaceae & Cymodocea & Cymodocea serrulata \\
Potamogetonaceae & Halodule & Halodule pinifolia \\
Potamogetonaceae & Halodule & Halodule uninervis \\
Potamogetonaceae & Syringodium & Syringodium isoetifolium \\
Potamogetonaceae & Thalassodendron & Thalassodendron ciliatum \\
\hline
\end{tabular}

Jenis-jenis lamun yang ditemukan di perairan Pantai Pandawa sebanyak dari 8 jenis lamun. Jenis lamun yang paling banyak ditemukan pada stasiun I adalah $T$. ciliatum. Hal tersebut dikarenakan substat pasir berkarang yang letaknya dekat dengan tubir merupakan substrat yang cocok untuk lamun T.ciliatum tumbuh. Faishol et al. (2016), menemukan bahwa lamun jenis $T$. ciliatum tumbuh pada dasar perairan yang cekung dan berdekatan dengan daerah tubir terumbu karang.

Jenis lamun yang paling banyak ditemukan pada stasiun II dan III yaitu $C$. serrulata dan ditemukan hampir diseluruh perairan Pantai Pandawa. Cymodocea serrulata dapat hidup bercampur dengan jenis lamun yang lain dan dapat tumbuh pada substrat pasir berkarang. Faishol et al., (2016), menemukan bahwa lamun $C$. 
serrulata tumbuh pada substrat pasir berlumpur atau pasir dengan pecahan karang pada daerah pasang-surut dan kadang-kadang bercampur dengan jenis lamun lain.

\section{Kerapatan Jenis dan Kerapatan Relatif}

Nilai kerapatan jenis ditemukan berbeda pada masing-masing stasiun. Nilai kerapatan jenis tertinggi ditemukan pada jenis $C$. serrulata pada stasiun III dan nilai kerapatan jenis terendah ditemukan pada jenis T. hemprichii pada stasiun I.

Kerapatan jenis secara keseluruhan tertinggi ditemukan pada stasiun III dengan rata-rata 683,8 tegakan/m2, sedangkan nilai kerapatan jenis terendah ditemukan pada stasiun II yaitu dengan rata-rata 150 tegakan $/ \mathrm{m} 2$. Kerapatan relatif dari lamun yang ditemukan di perairan Pantai Pandawa bervariasi dengan kerapatan relatif tertinggi ditemukan pada jenis C. serrulata pada stasiun 3 yaitu sebesar $65,8 \%$, diikuti dengan jenis $T$. ciliatum pada stasiun I dengan persentase sebesar $47,5 \%$ dan nilai terendah pada jenis $T$. hemprichii yang ditemukan pada stasiun I dengan persentase sebesar $1,5 \%$. Hasil kerapatan jenis dan kerapatan relatif lebih jelasnya dapat dilihat pada Gambar 5. dan Gambar 6.

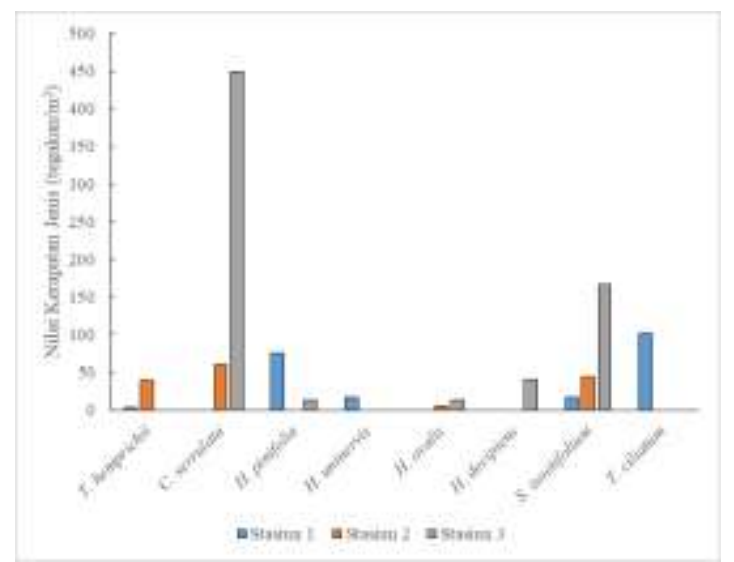

Gambar 5. Kerapatan Jenis Lamun

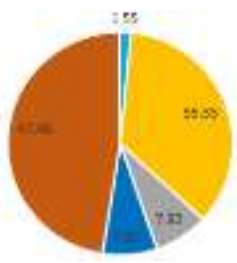

Stasiun I

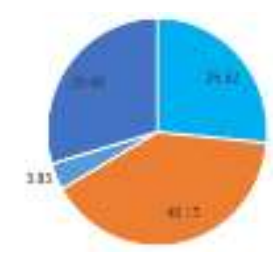

Stasiun II

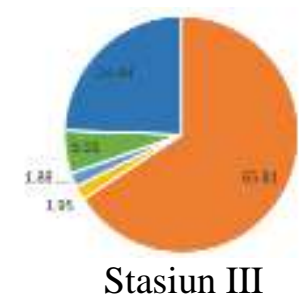

Gambar 6. Kerapatan Relatif

Keterangan:

$\begin{array}{ll}\text { T.hemprichii } & \text { S.isoetifolium } \\ \text { H.pinifolia } & \text { H.uninervis } \\ \text { H.ovalis } & \text { H.decipiens } \\ \text { C.serrulata } & \text { T.ciliatum }\end{array}$

Kerapatan jenis lamun di perairan Pantai Pandawa dapat dikategorikan sangat rapat, dengan kerapatan rata-rata 1.049,6 tegakan $/ \mathrm{m}^{2}$. Hal ini diperkuat oleh Gosari dan Haris (2012), bahwa nilai >175 dikategorikan kondisi lamun sangat rapat. Kerapatan jenis lamun terendah ditemukan pada stasiun II yaitu sebesar 150 tegakan $/ \mathrm{m}^{2}$ dan nilai tertinggi ditemukan pada stasiun III yaitu sebesar 683,8 tegakan $/ \mathrm{m}^{2}$. Penyebab dari hal tersebut adalah tingginya aktivitas manusia seperti kegiatan pariwisata pada stasiun II. Pernyataan diatas sesuai dengan Rahmawati (2011), yang mengatakan bahwa faktor tekanan lingkungan yang berasal dari manusia merupakan faktor yang paling berperan dalam penurunan vegetasi lamun.

Berdasarkan persentase nilai kerapatan relatif lamun, jenis lamun yang memiliki nilai persentase tertinggi di perairan Pantai Pandawa pada stasiun I adalah jenis $T$. ciliatum dengan nilai 
persentase $47.48 \%$ sedangkan pada stasiun II dan III jenis yang memiliki nilai persentase tertinggi yaitu C. serrulata dengan nilai persentase masing-masing sebesar 40.15 dan $65.81 \%$.

\section{Indeks Ekologi Lamun}

Indeks ekologi terdiri atas nilai indeks keanekaragaman, keseragaman dan dominansi. Nilai tertinggi dari indeks ekologi lamun di perairan Pantai Pandawa adalah indeks dominansi dan nilai terendah yaitu indeks keseragaman. Indeks keanekaragaman di masing masing stasiun memiliki nilai yang berbeda. Grafik indeks ekologi dapat dilihat pada Gambar 7.

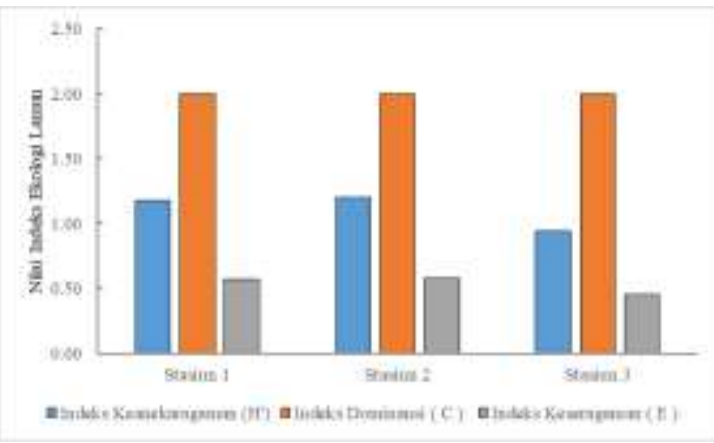

Gambar 7. Indeks Ekologi Lamun

Hasil indeks keanekaragaman di tiga stasiun memiliki nilai yang berbeda yaitu 1,$18 ; 1,2$; dan 0,94 berturut-turut pada stasiun I, II dan III. Insafitri (2010) mengemukakan bahwa nilai indeks keanekaragaman $1<\mathrm{H}^{\prime}<3$ termasuk dalam kriteria keanekaragaman jenis sedang dan nilai indeks keanekaragaman $\mathrm{H}^{\prime}<1$ termasuk dalam kriteria keanekaragaman jenis rendah. Nilai indeks keanekaragaman jenis pada stasiun I dan II termasuk dalam kategori keanekaragaman jenis sedang, sedangkan nilai keanekaragaman jenis pada stasiun III termasuk dalam kategori indeks keanekaragaman jenis rendah. Tinggi rendahnya keanekaragaman lamun yang tumbuh pada satu area berhubugan dengan faktor fisik maupaun kimia pada area tersebut (ikim mikro). Keanekaragaman jenis lamun pada stasiun I dan II hampir sama dimana suhu, kekeruhan dan $\mathrm{pH}$ pada kedua lokasi tersebut hampir sama juga, namun pada stasiun III, pH terukur relaitf lebih tinggi, dapat berpengaruh terhadap keanekaragaman jenis lamun yang tumbuh di pantai tersebut.

Nilai indeks dominansi di tiga stasiun memiliki nilai yang sama yaitu 1 . Berdasarkan nilai tersebut, bahwa indeks dominansi lamun di perairan Pantai Pandawa termasuk dalam kategori dominansi tinggi. Hal ini sesuai dengan Madduppa (2016), yang mengatakan nilai $0,75<\mathrm{C} \leq 1,0$ termasuk dalam kriteria dominansi tinggi.

Hasil indeks keseragaman menunjukkan angka 0,57; 0,58; dan 0,45 berturut-turut pada stasiun I, II dan III. Berdasarkan hal tersebut, dapat dikatakan bahwa indeks keseragaman pada stasiun I dan II termasuk dalam kriteria keseragaman sedang dan pada stasiun III termasuk dalam kriteria keseragaman rendah. Hal tersebut sesuai dengan pernyataan Madduppa (2016), bahwa nilai $0,5<\mathrm{E} \leq 0,75$ termasuk dalam kriteria keseragaman sedang dan nilai $0<\mathrm{E} \leq 0,5$ termasuk dalam kriteria keseragaman rendah.

\section{KESIMPULAN}

Jenis-jenis lamun yang terdapat di perairan Pantai Pandawa sebanyak 8 jenis, antara lain Thalassia hemprichii, Cymodocea serrulata, Halodule pinifolia, Halodule uninervis, Halophila ovalis, Halophila decipiens, Syringodium isoetifolium, dan Thalassodendron ciliatum. Hasil dari kerapatan jenis dan 
kerapatan relatif lamun menunjukkan bahwa kerapatan lamun di perairan Pantai Pandawa termasuk dalam kategori sangat rapat. Indeks keanekaragaman pada stasiun I dan II termasuk dalam kriteria keanekaragaman jenis sedang, sedangkan pada stasiun III termasuk dalam kriteria keanekaragaman jenis rendah. Indeks dominansi termasuk dalam kriteria dominansi tinggi. Indeks keseragaman pada stasiun I dan II termasuk dalam kriteria keseragaman sedang, sedangkan indeks keseragaman pada stasiun III termasuk dalam kriteria keseragaman rendah.

\section{UCAPAN TERIMA KASIH}

Penulis mengucapkan terimakasih Bendesa Adat Kutuh dan pihak Manajemen Pantai Pandawa yang telah memberikan izin untuk mengadakan penelitian di Pantai Pandawa.

\section{DAFTAR PUSTAKA}

Fahruddin, M. F., Yulianda, Setyobudiandi, I. 2017. Kerapatan dan Penutupan Ekosistem Lamun di Pesisir Desa Bahoi, Sulawesi Utara. Jurnal Ilmu dan Teknologi Kelautan Tropis, 9(1): 375 383.

Faishol, M. L., Nurcahyo, H., Nugroho, D. A. S., Rizky, M. A., Hutanto, Y., Roni, S., Utama, A. P., Budi, P., Supriyadi, S., Kertawijaya, L. S. 2016. Ekosistem Lamun di Taman Wisata Perairan Kepulauan Anambas. Pekanbaru: Loka Kawasan Konservasi Perairan Nasional Pekanbaru.

Gemilang, A. S., Kunarso, K., Handoyo, G. 2017. Pola Arus Laut Sebelum dan Sesudah Pembangunan Pelabuhan Tanjung Bonang Kabupaten Rembang. Jurnal Oseanografi, 6(2): 359 - 368.

Gosari, B. A. J., Haris, A. 2012. Studi Kerapatan dan Penutupan Jenis Lamun di Kepulauan Spermonde. Torani (Jurnal Ilmu Kelautan dan Perikanan), 22(3): 156 - 162.

Hamuna, B., Tanjung, R. H. R., Suwito, S., Maury, H. K., Alianto, A. 2018. Kajian Kualitas Air Laut dan Indeks Pencemaran Berdasarkan Parameter Fisika-Kimia Di Perairan Distrik Depapre, Jayapura. Jurnal Ilmu Lingkungan, 16(1): 35 - 43.

Insafitri, I. 2010. Keanekaragaman, Keseragaman dan Dominansi Bivalvia di Area Buangan Lumpur Lapindo Muara Sungai Porong. Jurnal KELAUTAN, 3(1): 54 - 59.

Madduppa, H. H. 2016. Modul Pelatihan: Teknik Analisis Kuantitatif Data Biologi Laut. Bogor: Institut Pertanian Bogor.

Minerva, A. F., Purwanti, P., Suryanto, A. 2014. Analisis Hubungan Keberadaan dan Kelimpahan Lamun Dengan Kualitas air di Pulau KarimunJawa, Jepara. Diponegoro Journal of Maquares, 3(3): 88 - 94.

Nurzahraeni, N. 2014. Keragaman Jenis dan Kondisi Padang Lamun di Perairan Pulau Panjang Kepulauan Derawan Kalimantan Timur . Skripsi. Makassar: Fakultas Perikanan dan Ilmu Kelautan, Universitas Hasanuddin.

Pratiwi, M. A., Ernawati, N. M. 2018. Struktur Komunitas Ekosistem Padang Lamun Pada Daerah Intertidal di Pantai Sanur, Bali. Ecotrophic, 12(1): 50 - 56.

Rahmawati, S. 2011. Ancaman Terhadap Komunitas Padang Lamun. Oseana, 36(2): $49-58$.

Sakaruddin, M. I. 2011. Komposisi Jenis, Kerapatan, Persen Penutupan dan Luas Penutupan Lamun di Perairan Pulau Panjang Tahun 1990 - 2010. Skripsi. Bogor: Fakultas Perikanan dan Ilmu Kelautan, Institut Pertanian Bogor. 
Sari, T. E. Y., Usman. 2012. Studi Parameter Fisika dan Kimia Daerah Penangkapan Ikan Perairan Selat Asam Kabupaten Kepulauan Meranti Propinsi Riau. Jurnal Perikanan dan Kelautan, 17(1): $88-100$.

Sjafrie, N. D., Hernawan, U. E., Prayudha, B., Supriyadi, I. H., Iswari, M. Y., Rahmat, Anggraini, K., Rahmawati, S., Suyarso. 2018. Status Padang Lamun di Indonesia 2018 Ver.02. Jakarta: Puslit Oseanografi-LIPI, September 2018.

Suherlan, S., Oetama, D., Arami, H. 2016. Keragaman Jenis Lamun di Perairan Pantai Waha Kecamatan Tomia Kabupaten Wakatobi. Jurnal Manajemen Sumber Daya Perairan, 1(3): $\quad 311-321$.

Supriyadi, I. H., Rositasari, R., Iswari, M. Y. 2018. Dampak Perubahan Penggunaan Lahan Terhadap Kondisi Padang Lamun di Perairan Timur Pulau Bintan Kepulauan Riau. Jurnal Segara, 14(1): 1 - 10 .

Tahril, T., Taba, P., Nafie, N. L., Noor, A. 2011. Analisis Besi dalam Ekosistem Lamun dan Hubungannya dengan Sifat Fisikokimia Perairan Pantai Kabupaten Donggala. Jurnal Natur Indonesia, 13(2): $105-111$.

Wagey, B. T., Sake, W. 2013. Variasi Morfometrik Beberapa Jenis Lamun di Perairan Kelurahan Tongkeina Kecamatan Bunaken. Jurnal Pesisir dan Laut Tropis, 3(1), 36 - 44.

Wangkanusa, M. S., Kondoy, K. I. F., Rondonuwu, A. B. 2017. Identifikasi Kerapatan dan Karakter Morfometrik Lamun Enhalus acoroides Pada Substrat yang Berbeda di Pantai Tongkeina Kota Manado. Jurnal Ilmiah Platax, 5(2), 210 -220 .

Wirawan, A. A. 2014. Tingkat Kelangsungan Hidup Lamun Yang
Ditransplantasi Secara Multispesies di Pulau Barranglompo. Skripsi. Makassar: Fakultas Perikanan dan Ilmu Kelautan, Universitas Hasanuddin. 